\title{
Graphical User Interface (GUI) for Mixed Mode Fracture Mechanics Analysis of Plates Using Crack Extension Technique
}

\author{
Ameen Ahmed Nassar \\ Department of Mechanical Engineering, College of Engineering, University of Basrah \\ *Corresponding Author: ameenaledani@yahoo.com
}

Copyright (C) 2014 Horizon Research Publishing All rights reserved.

\begin{abstract}
In this paper, a new approach for the mixed mode fracture mechanics analysis of plates using crack extension technique, by developing a new graphical user interface (GUI), has been introduced. The main objective of the paper is to show the usefulness and power of Matlab GUI in investigating and analyzing the effects of crack configurations and orientations on the calculation of stress intensity factors for cracked plates. The second purpose of this paper is to carry out an analysis using the developed GUI to simulate different crack configurations such as central-crack plate, single-edge plate, and double-edge plate. Illustrated problems in the field of analysis of fracture mechanics are carried out. The results show that the developed GUI is very useful for engineers, designers, and analysts of fracture mechanics problems.
\end{abstract}

Keywords Crack Extension Technique, Graphical User Interface, Mechanics Analysis

\section{Introduction}

Modeling and analysis of cracks in plates are an essential part of fracture mechanics. Plates are widely used in industrial applications but cannot effectively suppress loads in the present of cracks, with different configurations and orientations, without the aid of a computer tool for the analysis of such problems. The fracture mechanics analyses with different crack configurations require considerable analytical and computational effort. In order to prepare engineers to completely solve these problems numerically, the engineers must master a suitable programming environment. A proper modeling, analysis and calculations of stress intensity factors for cracks can be handled by the use of software like Matlab. MATLAB is a commercially available software package originally developed in the seventies by Cleve Moler, [1], for convenient numerical computations, especially matrix manipulations. Nowadays, it has grown to a high-level technical computing language and interactive developing environment, for algorithm development, data visualization, data analysis, and numerical computation, widely used in the academic world and in industry [2]. The combination of analysis capabilities, flexibilities, reliability, and powerful graphics makes Matlab the most suitable software package for engineers and scientists [3]. Matlab provides an interactive environment with a lot off reliable and accurate built-in mathematical functions. These functions provide solutions to a wide range of mathematical and engineering problems such as matrix algebra, linear and nonlinear systems, etc.

In this paper, the need for Matlab as a programming tool to design and build a graphical user interface (GUI) for the analysis of mixed mode fracture mechanics parameters (i.e. stress intensity factors) for plate using crack extension technique can be done using MATLAB/GUIDE environment [4].

\section{Governing Equations}

The Westergaard principal stress field equations for mode I stress intensity factor in infinite plate are given in reference [5] as follows:

$$
\begin{gathered}
\sigma_{1}=\frac{K_{I}}{(2 \pi r)^{1 / 2}} \cos \left(\frac{\theta}{2}\right)\left[1+\sin \left(\frac{\theta}{2}\right)\right] \\
\sigma_{2}=\frac{K_{I}}{(2 \pi r)^{1 / 2}} \cos \left(\frac{\theta}{2}\right)\left[1-\sin \left(\frac{\theta}{2}\right)\right] \\
\sigma_{3}=\left\{\begin{array}{l}
v\left(\sigma_{1}+\sigma_{2}\right) \ldots \ldots \ldots . . \text { Plane }- \text { strain } \\
0 \ldots \ldots \ldots \ldots \ldots \ldots \ldots \text { plane }- \text { stress }
\end{array}\right\}
\end{gathered}
$$

The displacement field for the same mode is also given as follows:

$$
u=\left(\frac{K_{I}}{4 \mu}\right)\left(\frac{r}{2 \pi}\right)^{1 / 2}\left[(2 \kappa-1) \cos \left(\frac{\theta}{2}\right)-\cos \left(\frac{3 \theta}{2}\right)\right]
$$




$$
v=\left(\frac{K_{I}}{4 \mu}\right)\left(\frac{r}{2 \pi}\right)^{1 / 2}\left[(2 \kappa+1) \sin \left(\frac{\theta}{2}\right)-\sin \left(\frac{3 \theta}{2}\right)\right]
$$

where,

$$
\begin{gathered}
\mu=\frac{E}{2(1+v)} \\
\kappa=\left\{\begin{array}{l}
(3-v) /(1+v) \ldots \ldots \ldots \text { Plane }- \text { stress } \\
(3-4 v) \ldots \ldots \ldots \ldots \ldots . . . . . \text { Plane }- \text { strain }
\end{array}\right\}
\end{gathered}
$$

The Brown solution for $\mathrm{K}_{\mathrm{I}}$ stress intensity factor of finite plate under tension load for different crack configuration, limited to half crack length to plate width ratio $(\mathrm{a} / \mathrm{W})=0.6$, are given in reference [6] as follows:

$$
K_{I}=C \sigma \sqrt{\pi a}
$$

Where for:

(i) Central crack Plate

$$
C=1+0.256\left(\frac{a}{W}\right)-1.152\left(\frac{a}{W}\right)^{2}+12.2\left(\frac{a}{W}\right)^{3}
$$

(ii) Single edge crack plate

$$
\begin{aligned}
& C=1.12-0.231\left(\frac{a}{W}\right)+10.55\left(\frac{a}{W}\right)^{2}- \\
& -21.72\left(\frac{a}{W}\right)^{3}+30.39\left(\frac{a}{W}\right)^{4}
\end{aligned}
$$

(iii) Double edge crack plate

$$
C=\frac{1.122-0.561\left(\frac{a}{W}\right)-0.205\left(\frac{a}{W}\right)^{2}+0.471\left(\frac{a}{W}\right)^{3}-0.190\left(\frac{a}{W}\right)^{4}}{\sqrt{1-\left(\frac{a}{W}\right)}}
$$

$\sigma$ is the applied tensile stress, $a$ is half the crack length, and $\mathrm{W}$ is the plate width.

The elastic stress field in the vicinity of a crack tip, as given by the previous equations, shows that as $r$ tends to zero the stresses become infinite (i.e. stress singularity at the crack tip). Since many structural materials deform plastically above the yield stress, there will be in reality a plastic zone surrounding the crack tip, and the elastic solution for such situations, may require modification to some of the linear elastic fracture mechanics concepts. The two physically acceptable yield criteria for metals and alloys are the well-known Tresca and von Mises yield criteria. In this work the von Mises criterion will be considered which requires that the distortion energy per unit volume approaches a critical value. This criterion can be expressed in terms of principal stresses as follows [7]:

$$
\left(\sigma_{1}-\sigma_{2}\right)^{2}+\left(\sigma_{2}-\sigma_{3}\right)^{2}+\left(\sigma_{3}-\sigma_{1}\right)^{2}=2 Y^{2}
$$

Where $\mathrm{Y}$ is the yield stress of material.

The summation of the square terms in the above equation termed the equivalent stress $\left(\sigma_{\mathrm{e}}\right)$ which represents the strength of the plasticity near the crack tip and can be plotted in a contour form to show the boundary of the plastic zone surround the crack tip.

\section{Analysis Procedure}

The steps for the analysis procedure of calculating stress intensity factors using the crack extension technique developed by the author in Reference [8]. A matlab GUI is developed in this paper based upon these steps to study the effects of different crack configurations on different analysis parameters such as stresses and displacements of cracked plates. To validate the procedure and the GUI, three case studies of cracked plates with different configurations are chosen for this purpose and the results are shown in the next section.

\section{Results and Discussion}

An Aluminum plate of dimension $50 \mathrm{~mm}$ x $20 \mathrm{~mm}$ and thickness $1 \mathrm{~mm}$, with initial crack length of $6 \mathrm{~mm}$, given in Reference [9], with modulus of elasticity $70 \mathrm{GN} / \mathrm{m}^{2}$, and possion's ratio 0.33 and Yield stress of $17.5 \mathrm{MN} / \mathrm{m}^{2}$ is considered according to Reference [10], (yield stress for Aluminum is $15-20 \mathrm{MPa}$ ).

\section{(a)- Central-crack plate}

The plate considered to demonstrate the analysis is a central cracked plate of width $W$ and half crack length $a$. using the developed GUI. The main menu shown in Figure (1), will allow the user to choose the crack configuration required for the analysis.

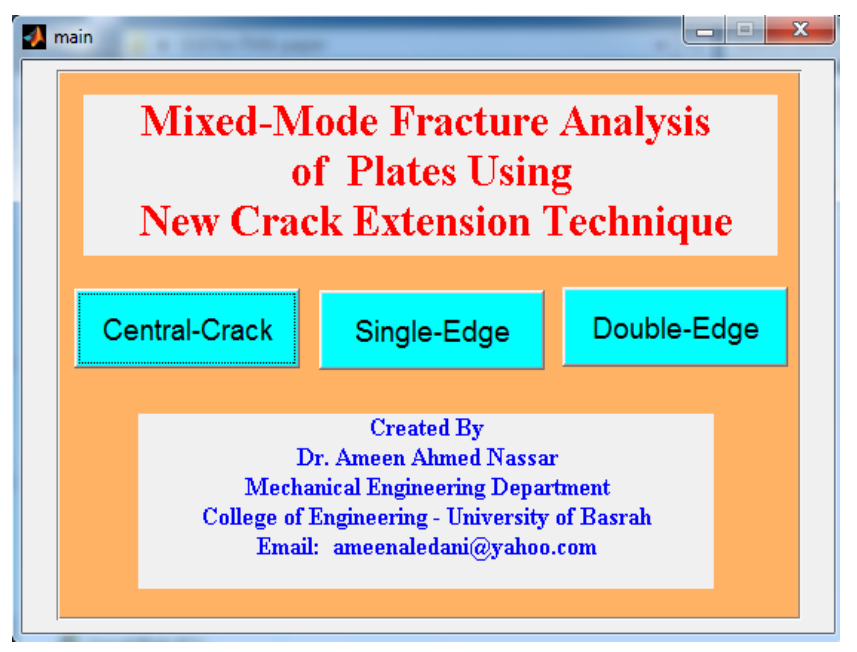

Figure 1. Main menu.

The analysis starts by clicking on the Central-Crack bush 
button, the window shown in Figure (2) will appear.

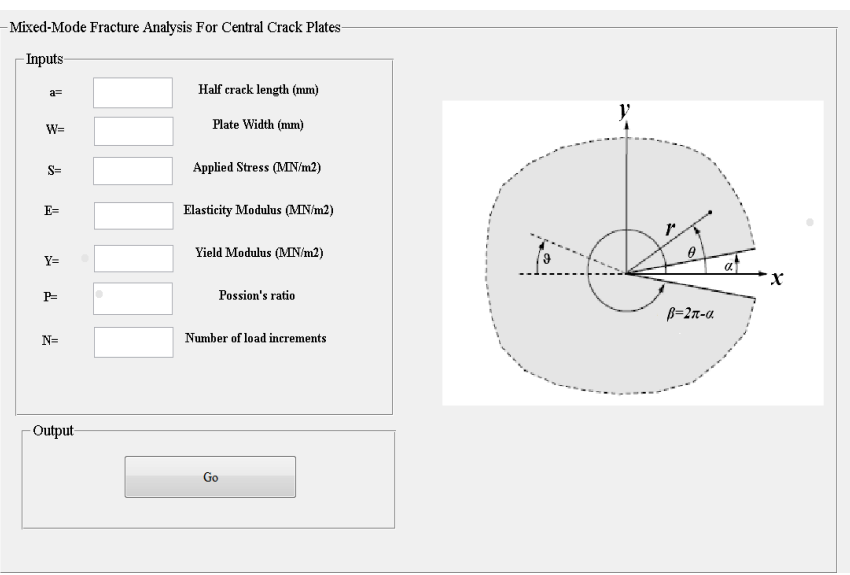

Figure 2. Central-Crack window.

By inserting the required data and considering an $a / W$ ratio of 0.1 and a 10 stress increments starting at a stress value which just cause yielding. The results for this analysis are as follows:

Figure (3) shows the behavior of the calculated stress intensity factors $\mathrm{K}_{\mathrm{I}}, \mathrm{K}_{\mathrm{II}}$ for each load increment and crack length value, as well as shown the behavior of the crack length due to the increase in load increment. It is clear from the figure that the $\mathrm{K}_{\mathrm{I}}, \mathrm{K}_{\mathrm{II}}$ values increases nonlinearly with the increase of the load increment and the calculated crack length values.
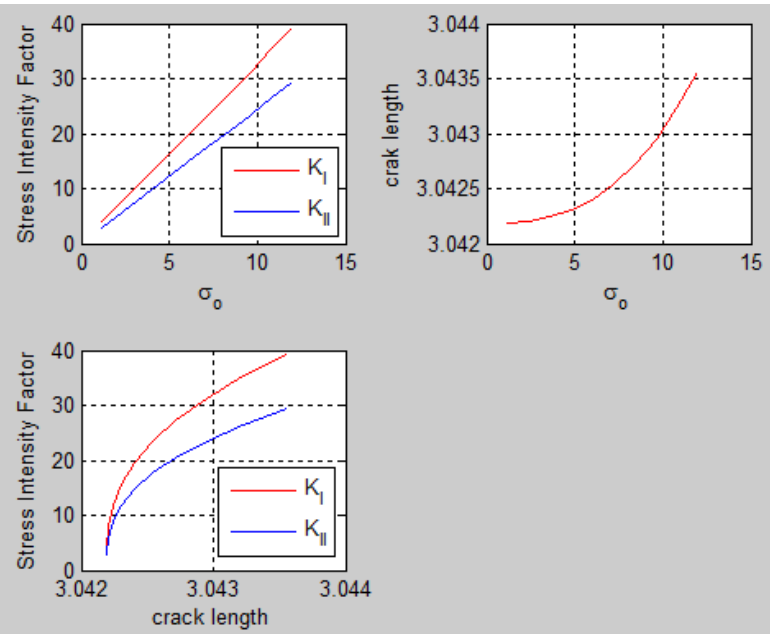

Figure 3. Behavior of the calculated stress intensity factors $\mathrm{K}_{\mathrm{I}}, \mathrm{K}_{\mathrm{II}}$ for each load increment and crack length value for central-crack plate.

Figure (4) illustrate the behavior of displacements with the crack angle and the crack tip radius for each stress increment starting with initial half crack length of 2 . It is clear from this figure that the behavior of the displacements is somehow periodic with both crack angle $\theta$ and crack tip radius $\boldsymbol{r}$. Figures (5) and (6) presented the calculated Cartesian, principal and equivalent stresses and the yield stress for each crack length. These figures are very important because they show the behavior of the calculated stresses especially the equivalent stress with the given yield stress of the material which is an indication of the failure of the plate material.
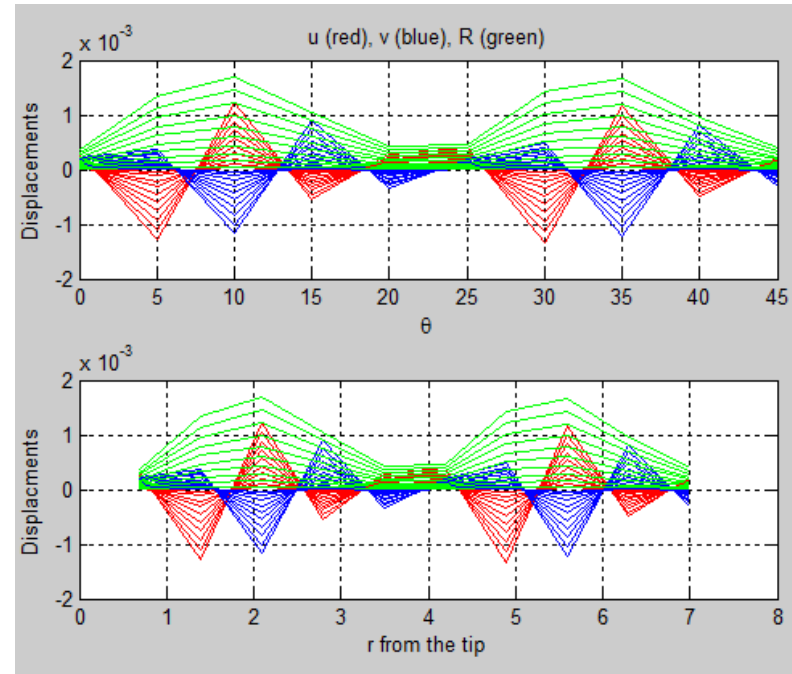

Figure 4. Behavior of displacements with the crack angle and the crack tip radius of each stress increment for central-crack plate.
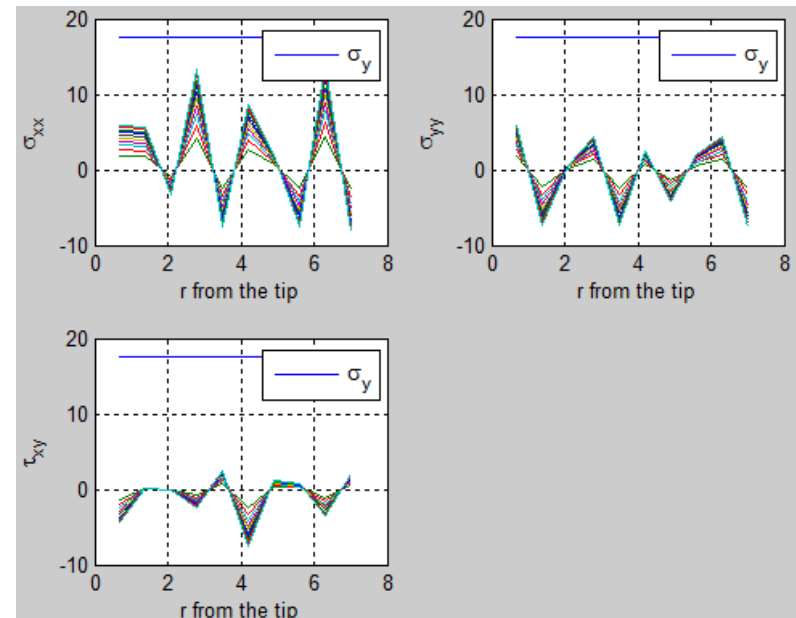

Figures 5. Cartesian stresses and the yield stress at each crack length for central-crack plate.
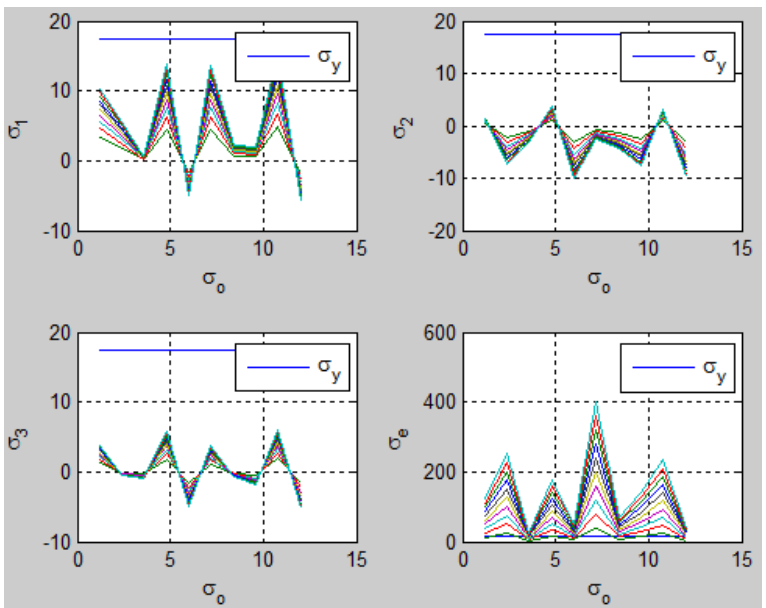

Figures 6. Principal stresses and the yield stress at each crack length for central-crack plate. 


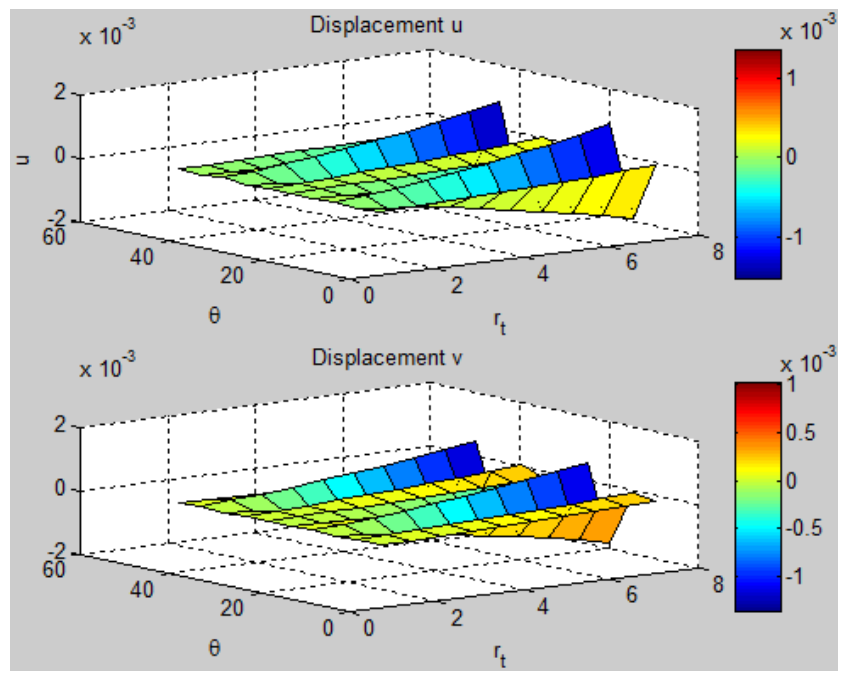

Figure 7. Behavior of displacements of each crack angle and crack tip radius for central-crack plate.
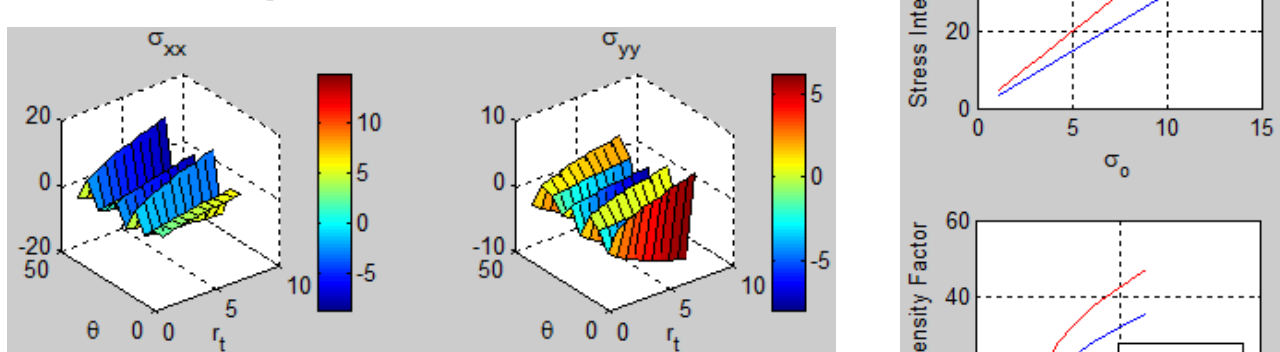

Figure (7) shows the behavior of the calculated displacements for each crack angle and crack tip radius. This combined relation shows clearly the interaction between the crack angle and the crack tip radius for mixed mode fracture analysis. Figures (8) and (9) are the illustration for the behavior of the Cartesian, the principal and the equivalent stresses for each crack angle and crack tip radius. It is clear from these figures that the behavior is not linear and the calculated values are behaving periodically with the increase of the crack angle and the crack tip radius. These figures are very important for designers since they described the behavior of the mixed mode fracture mechanics analysis in a new illustration which gives a clear picture for the relation between the different parameters presented in this research.
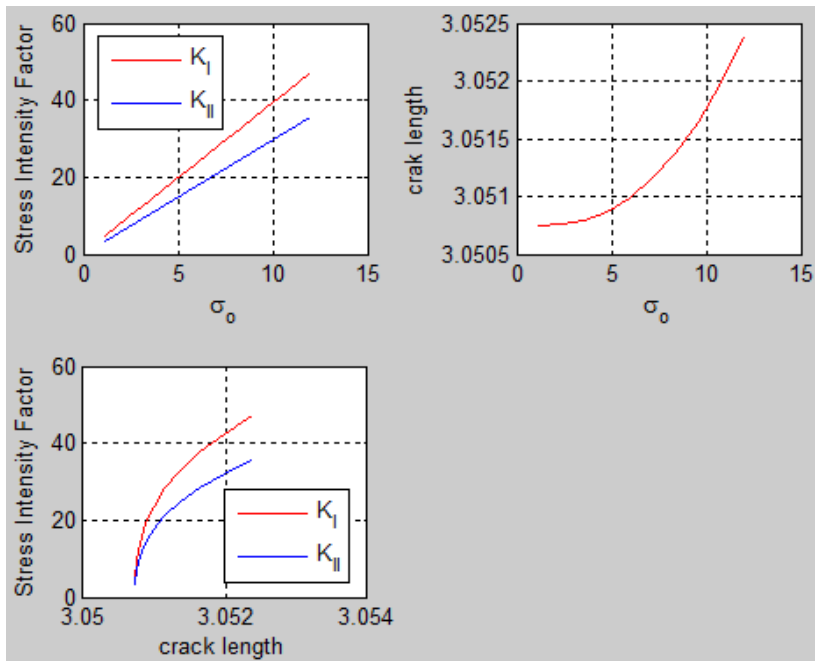

Figure 10. Behavior of the calculated stress intensity factors $\mathrm{K}_{\mathrm{I}}, \mathrm{K}_{\mathrm{II}}$ for each load increment and crack length value for single-edge crack plate.
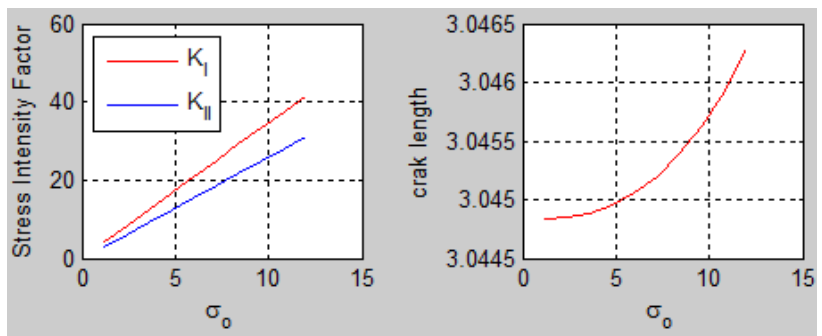

Figures 8. Behavior of the Cartesian stresses at each crack angle and crack tip radius for central-crack plate.
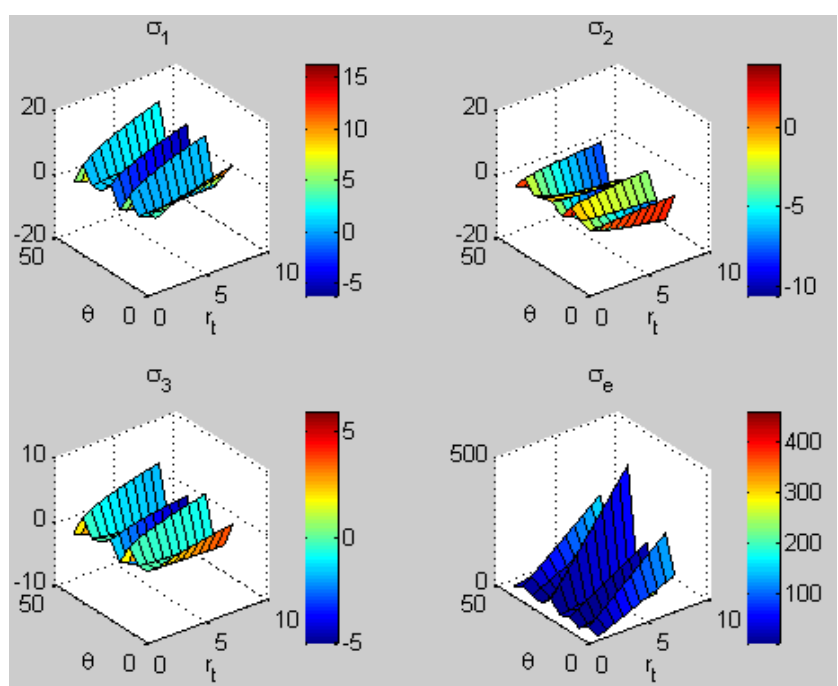

Figures 9. Behavior of the Principal and equivalent stresses at each crack angle and crack tip radius for central-crack plate.

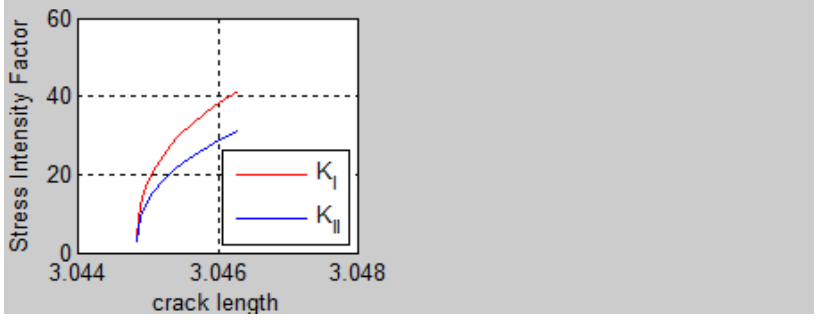

Figure 11. Behavior of the calculated stress intensity factors $K_{I}, K_{\text {II }}$ for each load increment and crack length value for double-edge crack plate

\section{(b)- Other crack configuration}

The other crack configurations considered for the analysis are the single-edge crack plate and the double- edge crack plate, in which their results are presented in Figures (10) and 
(11) respectively. These figures shows the behavior of the calculated stress intensity factors $\mathrm{K}_{\mathrm{I}}, \mathrm{K}_{\mathrm{II}}$ for each load increment and crack length value, as well as the behavior of the crack length due to the increase in load increment for single-edge crack and double-edge crack plates respectively. Comparing these figures with Figure (3), shows clearly that different configurations of crack gives different behaviors for the calculated $\mathrm{K}_{\mathrm{I}}$ and $\mathrm{K}_{\mathrm{II}}$ values as well as the calculated crack length values for different crack increments.

Finally, it is clear from these figures that, the single-edge crack plate configuration exhibit the largest extension among the other configurations.

\section{Conclusions}

From the above analysis, the following conclusions can be drawn:

1. The GUI for mixed mode fracture analysis of plates presented in this paper shown to be very convenient and essential for describing the behavior of stress intensity factors, and stress states at different crack angle and crack tip radius for different crack configurations.

2. The developed GUI reduced the need for sophisticated numerical analyses such as finite elements, boundary elements, or J-integrals which require more time and effort, to calculate the same parameters tackled in this research.

\section{REFERENCES}

[1] Mathworks, Inc,"Matlab User's Guide", (1991).

[2] Hingham, D. J.,"Matlab Guide", Philadelphia Society for Industrial and Applied Mathematics, (2005).

[3] Mathworks, Inc,"MATLAB, the Language of Technical Computing", (2002).

[4] Mathworks, Inc,"Building GUI's with MATLAB",Version 5, (1996).

[5] Al-Edani A. A. N. ,"Efficient Fracture Mechanics Programming System for Linear and Non-Linear Problems Using Finite-Element and Boundary-Element Methods", Ph. D. Thesis, Cranfield University, UK, 1990.

[6] Azuz H. N., "Linear Elastic Fracture Mechanics Analysis Using Meshless Local Petrov-Galerkin Method With Unconventional Support Domains", M. Sc. Thesis, University of Basrah, Iraq, 2011.

[7] Ewalds H. L. and Wanhill R. J. H., "fracture mechanics", Edward Arnold Ltd, USA, Third imprint, 1986.

[8] Nassar A. A., "Evaluation of Critical Stress Intensity Factor (Kic) for Plates Using New Crack Extension Technique", Eng. \& Tech. Journal, Vol. 31, No. 4, 2013.

[9] Nassar, A. A., "The 9-node Lagrangian Finite Element as Crack Element for Fracture Mechanics Problems", Proceeding of $2^{\text {nd }}$ Basrah Conference of Mechanical Engineering Research' 20-21 April 1993, College of Engineering, University of Basrah, Basrah, Iraq.

[10] Howtson, A. M., Lund P. G., Todd J. D.,"Engineering Tables and Data", P.41, Chapman and Hall Publishers, 1991 